\title{
Residual stromal bed thickness correlates with regression of myopia after LASIK
}

\author{
This article was published in the following Dove Press journal: \\ Clinical Ophthalmology \\ 12 October 2016 \\ Number of times this article has been viewed
}

\author{
Kosuke Ogasawara \\ Tsuyoshi Onodera \\ Ogasawara Eye Clinic, Morioka, Japan
}

Purpose: The purpose of this study was to evaluate the correlation between residual stromal bed thickness (hereinafter bed thickness) and regression of myopia after LASIK, taking into consideration the long-term outcomes.

Subjects and methods: A total of 177 patients (309 eyes) and 41 patients (70 eyes) were retrospectively reviewed at 5 and 10 years after surgery, respectively. These patients were also continuously examined throughout the study. All patients underwent laser in situ keratomileusis (LASIK) for myopia in our clinic and scored at least 1.0 (0 logMAR) uncorrected distance visual acuity (UCVA) 1 month after surgery. Bonferroni-Dunn method and Student's $t$-test were used for statistical analyses.

Results: Cases with a refractive value (spherical equivalent) of less than -6.0 D (Group A) were compared to those with $-6.1 \mathrm{D}$ or higher (Group B). There was a statistically significant decrease in Group B UCVA of $0.04 \log$ MAR and $0.12 \log$ MAR at 5 and 10 years after surgery, respectively. With regard to the relationship between regression of myopia and bed thickness in the long-term, there was a significantly higher frequency of regression of myopia in cases with less than $350 \mu \mathrm{m}$ bed thickness compared to those with $350 \mu \mathrm{m}$ and more, in a surgical volume of more than $-6.1 \mathrm{D}$ (Group B).

Conclusion: The present study indicates that bed thickness correlates with regression of myopia after LASIK and enough bed thickness is important to maintain good UCVA in the long-term. Keywords: LASIK, regression, residual stromal bed thickness

\section{Introduction}

Several retrospective studies have examined the long-term postoperative results of laser in situ keratomileusis (LASIK) ${ }^{1-5}$ and proposed various mechanisms that could lead to a regression of myopia. These include changes in corneal refraction of the corneal anterior surface, anterior displacement of the posterior surface of the cornea, ${ }^{6-9}$ higher degree of astigmatism, ${ }^{10}$ axial length elongation during the long-term follow-up period, and hardening of lens nucleus by age. ${ }^{11}$ However, there have not been any studies investigating the correlation between regression of myopia and residual stromal bed thickness (hereinafter bed thickness) more than 10 years after surgery. We have previously suggested the correlation between regression of myopia and bed thickness in a short-term study. ${ }^{8}$ In the present study, we investigated the importance of bed thickness to maintain good uncorrected distance visual acuity (UCVA) after LASIK based on the long-term outcomes.

\section{Subjects and methods Subjects}

A total of 177 patients (309 eyes) and 41 patients (70 eyes) were retrospectively reviewed at 5 and 10 years after surgery, respectively. These patients were also
Correspondence: Kosuke Ogasawara

Ogasawara Eye Clinic, 3-10-12,

Takamatsu, Morioka 020-0I I4, Japan

Tel +8I 196623223

Fax +8I I9662733।

Email oga-koke@diamond.broba.cc
Clinical Ophthalmology 2016:10 |977-1981

1977 
continuously examined throughout the study. All the patients underwent LASIK for correction of myopia at our clinic from July 2001 and scored at least 1.0 (0 logMAR) UCVA 1 month after surgery. Details of the preoperative data and characteristics of subjects are summarized in Tables 1 and 2 . Patients with postoperative complications and enhancement cases were not included in this study.

\section{Surgical technique}

In those cases analyzed for the present study, two surgeons performed LASIK using microkeratome MK-2000 ${ }^{\circledR}$ (NIDEK Co., Ltd.) for all cases of corneal flap preparation, and the Excimer laser system EC-5000 (NIDEK Co., Ltd.) for laser ablation. Flap thickness of analysis cases in this study was $110.2 \pm 15 \mu \mathrm{m}$ (mean \pm standard deviation). Standard LASIK with an optical zone of $6 \mathrm{~mm}$ and transitional zone of $7 \mathrm{~mm}$ was performed. Corrected astigmatism was $-0.71 \pm 0.8 \mathrm{D}$ (mean \pm standard deviation). Corneal shape analysis was carried out using Orbscan ${ }^{\circledR}$. Corneal thickness was measured using pachymeter DGH-500 ${ }^{\circledR}$ (DGH Co., Ltd.), preoperatively, intraoperatively, and postoperatively. Bed thickness was determined by subtracting the ablated volume of the cornea from the remaining value of corneal central thickness before intraoperative excimer laser ablation after flap reverse.

\section{Methods}

An examination is performed at our clinic on the day after surgery, followed by 1 week, 1 month, 3 months, 6 months, 1 year, and 2 years after surgery. Then, the patient is advised to return to the clinic once a year. Cases of noncompliance where subjects returned irregularly for follow-up examinations were excluded from the study. This study considered only those cases that could be continuously examined throughout the postoperative periods of 1 month, 6 months, 5 years, and 10 years after surgery.

Postoperative safety index, visual acuity, efficacy index, and corneal refraction were among the data collected. Postoperative change of corneal refraction in 5 and 10 years

Table I Details of preoperative data and characteristics of subjects in cases of 5 years after LASIK

\begin{tabular}{|c|c|c|c|c|}
\hline \multirow{2}{*}{$\begin{array}{l}\text { Preoperative data } \\
\text { and characteristics } \\
\text { of subject }\end{array}$} & \multicolumn{2}{|l|}{ Group A } & \multicolumn{2}{|l|}{ Group B } \\
\hline & Male & Female & Male & Female \\
\hline Eyes & 182 & & 127 & \\
\hline Number of patients & 34 & 69 & 19 & 55 \\
\hline $\begin{array}{l}\text { Mean age at surgery } \\
\text { (years) }\end{array}$ & 34.0 & 33.7 & 34.7 & 24.0 \\
\hline $\begin{array}{l}\text { Refraction } \\
\text { (spherical equivalent) } \\
\text { (mean } \pm S D)(D)\end{array}$ & $-4.29 \pm 1.19$ & & $-8.22 \pm 1.75$ & \\
\hline
\end{tabular}

Abbreviations: LASIK, laser in situ keratomileusis; SD, standard deviation; D, diopter.
Table 2 Details of preoperative data and characteristics of subjects in cases of 10 years after LASIK

\begin{tabular}{|c|c|c|c|c|}
\hline \multirow{2}{*}{$\begin{array}{l}\text { Preoperative data } \\
\text { and characteristics } \\
\text { of subjects }\end{array}$} & \multicolumn{2}{|l|}{ Group A } & \multicolumn{2}{|l|}{ Group B } \\
\hline & Male & Female & Male & Female \\
\hline Eyes & 38 & & 32 & \\
\hline Number of patients & 13 & 9 & 7 & 12 \\
\hline $\begin{array}{l}\text { Mean age at surgery } \\
\text { (years) }\end{array}$ & 35.7 & 40.3 & 34.4 & 39.7 \\
\hline $\begin{array}{l}\text { Mean refraction } \\
\text { (spherical equivalent) } \\
(\text { mean } \pm \text { SD) }(D)\end{array}$ & $-4.49 \pm 1.08$ & & $-8.63 \pm 2.00$ & \\
\hline
\end{tabular}

Abbreviations: LASIK, laser in situ keratomileusis; SD, standard deviation; D, diopter.

was evaluated by comparing with the keratometric value (diopter: hereinafter D) of 6 months after surgery. Furthermore, cases with a corrected refractive value (spherical equivalent) of less than $-6.0 \mathrm{D}$ (hereinafter referred to as Group A) were compared with cases with a corrected refractive value $-6.1 \mathrm{D}$ and higher (hereinafter referred to as Group B). In addition, long-term progression of vision and corneal refraction were considered with regard to bed thickness of more or less than $350 \mu \mathrm{m}$ after LASIK. We described here the meaning of bed thickness $350 \mu \mathrm{m}$. When surgical ablation volume was set at refractive value of $-6.0 \mathrm{D}$ in cases of myopia correction by LASIK, ablation volume was $\sim 90 \mu \mathrm{m}$. As average central corneal thickness of Japanese individual is around $540 \mu \mathrm{m}$, the value chosen to compare bed thickness was set at $350 \mu \mathrm{m}$, which is $540 \mu \mathrm{m}$ minus $190 \mu \mathrm{m}$ including flap thickness. An efficacy index (postoperative UCVA/preoperative corrected distance visual acuity) was used to evaluate the effectiveness of LASIK. A safety index (postoperative corrected distance visual acuity/preoperative corrected distance visual acuity) was used to evaluate the safety of the procedure. Regarding vision, the value of visual acuity fraction was converted to $\log$ MAR vision and set as the database.

With regard to statistical analysis, Bonferroni-Dunn method for multiple comparisons (Figures 1 and 2B) and Student's $t$-test for two groups (Figures 2A, 3, and 4) were used. The significance level of $5 \%$ was used.

Written informed consent was obtained from all the subjects. The study was conducted in accordance with the tenets of the Declaration of Helsinki and with the approval of the Ogasawara Eye Clinic's ethical review board.

\section{Results Safety of LASIK}

The overall safety index of all targeted cases at 5 and 10 years after surgery was 1.15 and 1.18 , respectively. Moreover, good results of the efficacy index were obtained in both Group A (less than $-6.0 \mathrm{D})$ and Group B (-6.1D or higher). Thus, the efficacy 


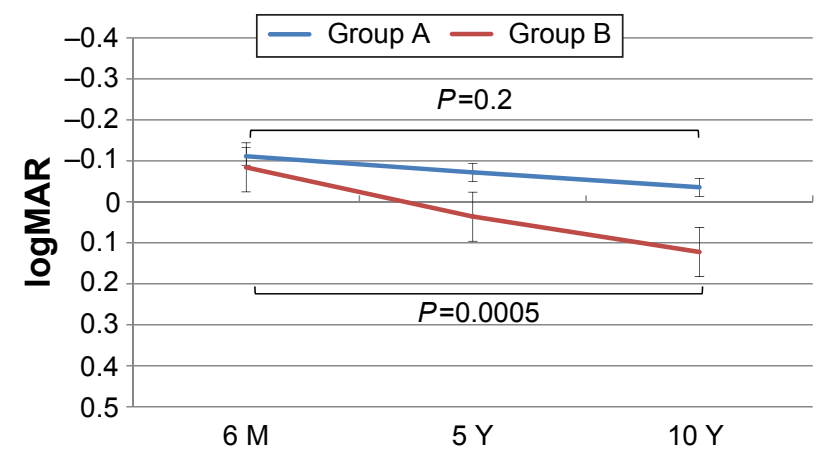

Figure I The time course and changes of UCVA in this study and comparison of UCVA in cases of Group A (corrected refractive value of less than $-6.0 \mathrm{D}$ ) and Group B (corrected refractive value of higher than $-6.1 \mathrm{D}$ ).

Note: There was a significant decrease of UCVA in Group B at 10 years after LASIK. Abbreviations: UCVA, uncorrected distance visual acuity; LASIK, laser in situ keratomileusis; M, months; $Y$, years; D, diopter.

index of Group A and Group B was 1.18 and 1.15 at 5 years after surgery and 1.18 and 1.08 at 10 years after surgery.

\section{Postoperative vision and effectiveness of LASIK}

A statistically significant difference was observed in postoperative UCVA with an average value of -0.02 $\log$ MAR and $0.04 \log M A R$ at 5 and 10 years after surgery, respectively, compared to $-0.1 \log$ MAR 6 months after surgery in all the cases. When compared with cases of Group A and Group B, there was a statistically significant decrease in Group B UCVA of $0.04 \log$ MAR and $0.12 \log M A R$ at 5 and 10 years after surgery, respectively (Figure 1). These results are reflected by the efficacy index where Group A and Group B scored 1.00 and 0.86 at 5 years after surgery and 0.94 and 0.68 at 10 years after surgery, respectively.

Changes in postoperative vision were verified by bed thickness. There was a trend toward a significant difference in UCVA between cases of bed thickness above $350 \mu \mathrm{m}$ and those less than $350 \mu \mathrm{m}$ at 10 years after surgery in Group B (Figure 2A). Furthermore, when the ablation volume by LASIK was set as $92-98 \mu \mathrm{m}$ (approximately for -7.0 to $-7.8 \mathrm{D}$ ) in cases of Group B with bed thickness of more than $350 \mu \mathrm{m}$ and less than $350 \mu \mathrm{m}$, a more significant decrease in UCVA in cases with bed thickness of less than $350 \mu \mathrm{m}$ after surgery was apparent (Figure 2B).

\section{Corneal refraction}

A change in the degree of corneal refraction is considered an important factor for a decreased postoperative UCVA in the long-term. With regard to the change in corneal refraction, a significant increase of keratometric value (D) was observed in Group B compared to Group A (Figure 3). Furthermore, when changes in keratometric value beyond 6 months after surgery were examined in the two groups (Group A and B), a significant increase in keratometric value was observed in both Group A (Figure 4A) and Group B (Figure 4B) with bed thickness of less than $350 \mu \mathrm{m}$ from $0.34 \mathrm{D}$ at 5 years to $0.54 \mathrm{D}$ at 10 years, and with bed thickness of more than $350 \mu \mathrm{m}$ from $0.41 \mathrm{D}$ at 5 years to $0.70 \mathrm{D}$ at 10 years, respectively. Conversely, among cases with bed thickness of more than $350 \mu \mathrm{m}$, a statistical difference of keratometric value was not observed in both Group A (Figure 4A) and Group B (Figure 4B).

\section{Discussion}

The fact that the safety index of all target cases at 5 and 10 years after surgery was 1.15 and 1.18 , respectively confirmed the safety of LASIK.

Regarding UCVA after LASIK, the frequency of regression of myopia has been reported to be higher in cases with more surgical volume. ${ }^{1,3,4}$ Consistent with these reports, our
A

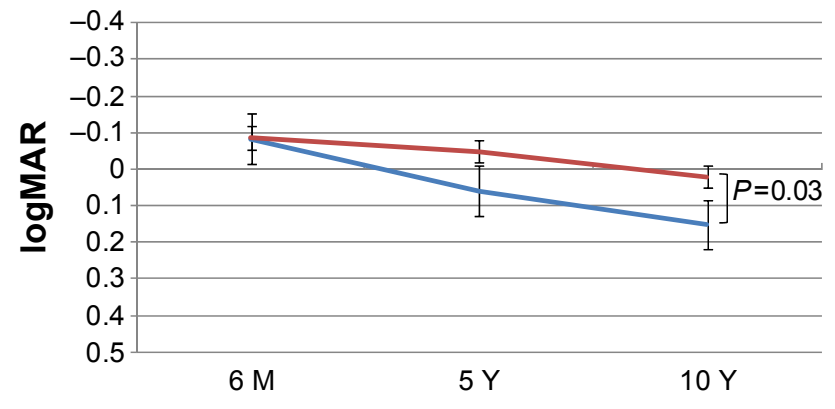

B

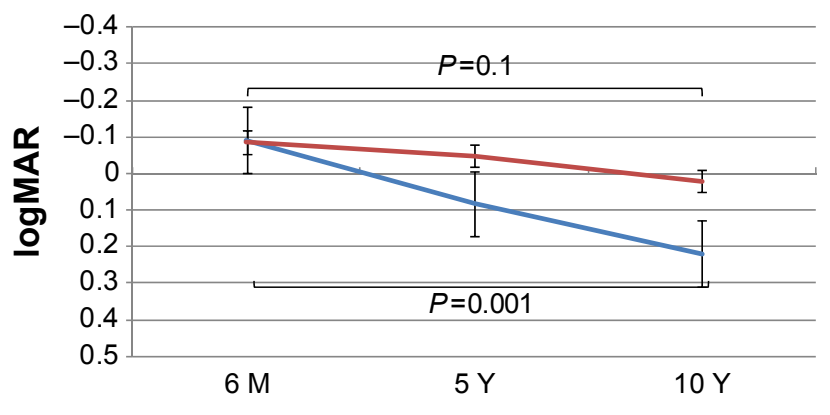

Residual corneal bed thickness less than $350 \mu \mathrm{m}$

Residual corneal bed thickness more than $350 \mu \mathrm{m}$

Figure 2 Changes of UCVA in verified bed thickness in Group B. Significant decrease of UCVA in cases of Group B with bed thickness of less than $350 \mu \mathrm{m}$ compared to those with more than $350 \mu \mathrm{m}$ at 10 years after LASIK was observed (A). When the ablation volume by LASIK was set as $92-98 \mu \mathrm{m}$ (approximately for -7.0 to $-7.8 \mathrm{D}$ ) in Group B, a more significant decrease in UCVA in cases with bed thickness of less than $350 \mu \mathrm{m}$ after surgery was apparent (B).

Abbreviations: UCVA, uncorrected distance visual acuity; LASIK, laser in situ keratomileusis; M, months; Y, years; D, diopter. 
(D)

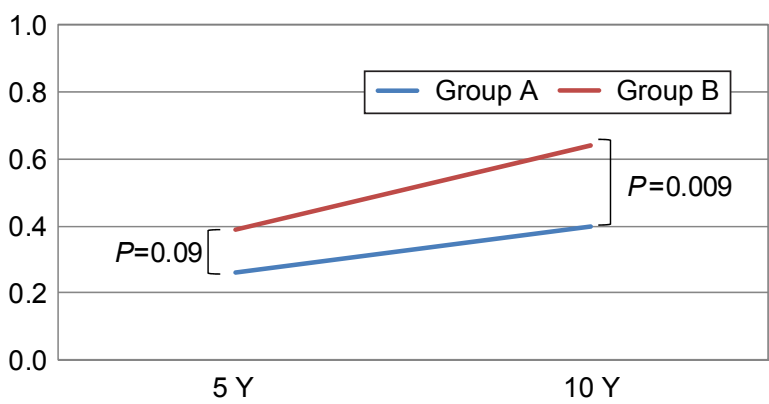

Figure 3 Difference in keratometric value (D) to show changing of corneal refraction in Group A and Group B. A significant increase of keratometric value was observed in Group B at 10 years after LASIK.

Abbreviations: LASIK, laser in situ keratomileusis; $Y$, years; D, diopter.

study observed a trend toward a decrease in UCVA over a longer term in Group B with a surgical volume of more than -6.1 D compared to Group A with a surgical volume of less than $-6.0 \mathrm{D}$. When visual acuity was compared with that at 6 months after surgery, a significant decrease of UCVA was observed in Group B after surgery (Figure 1). This is reflected by the changes in efficacy index over time. A significant decrease in efficacy index was reported in Group B at 10 years after surgery. Conversely, no significant difference was observed in UCVA or efficacy index in Group A even after 5 and 10 years after LASIK.

We have previously reported evidence of a correlation between regression of myopia and bed thickness in the short-term. ${ }^{8}$ In this study, we investigated regression of myopia in the long-term, comparing bed thickness of more than $350 \mu \mathrm{m}$ with that of less than $350 \mu \mathrm{m}$. A trend toward a significant difference in UCVA was observed at 10 years after surgery. When comparing the correlation between bed thickness in Group A and Group B, no significant difference was observed in Group A for both cases with bed thickness of more or less than $350 \mu \mathrm{m}$. However, a significant difference was observed at 10 years after LASIK in Group B (Figure 2A). Furthermore, the data that a more significant decrease in UCVA with bed thickness of less than $350 \mu \mathrm{m}$ at 10 years after surgery in Group B when the ablation volume by LASIK was set as $92-98 \mu \mathrm{m}$ (approximately for -7.0 to $-7.8 \mathrm{D}$ ) confirmed the importance of bed thickness in maintaining a good UCVA in high myopia (Figure 2B). Taken together, the data suggest the possibility of keeping good UCVA in the long-term after LASIK even in Group B, if the bed thickness is more than $350 \mu \mathrm{m}$. On the other hand, a significant decrease in vision was observed in Group B with a bed thickness of less than $350 \mu \mathrm{m}$.

With regard to the change in corneal refraction, Group A and Group B were compared as the number of cases with decreased UCVA after LASIK were found to be higher in Group B. A significant increase in keratometric value was observed in Group B compared to Group A (Figure 3). Moreover, in cases where bed thickness was less than $350 \mu \mathrm{m}$, the degree of changes in keratometric value increased over the years, when compared with cases where bed thickness was $350 \mu \mathrm{m}$ or more (Figure 4), indicating a correlation in regression.

It is well established that the frequency of regression of myopia increases as the degree of refractive correction by LASIK ${ }^{1,3,4}$ However, there have not been any studies investigating the correlation between this regression and bed thickness. As such, our study provides novel and important data with regard to this relationship in the long-term. The present study is an indication of the limit of refractive surgical volume, so as to maintain UCVA in the long-term after LASIK surgery.
A (D)

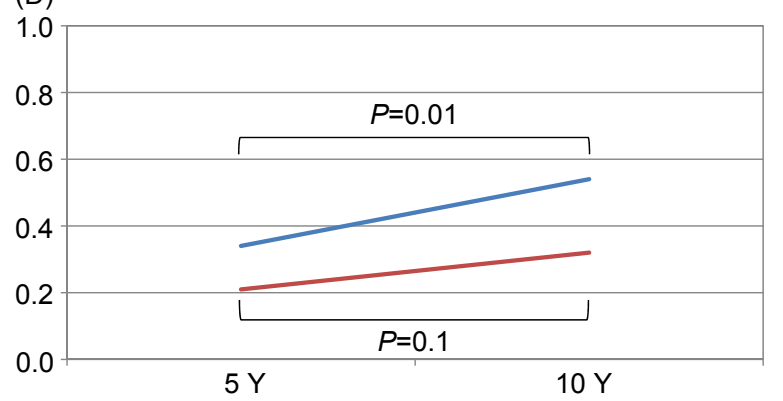

B

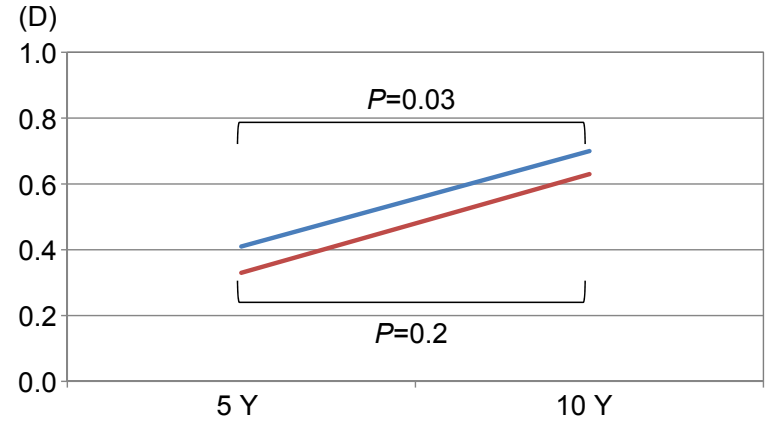

— Residual corneal bed thickness less than $350 \mu \mathrm{m} \quad$ Residual corneal bed thickness more than $350 \mu \mathrm{m}$

Figure 4 Changes of keratometric value (D) of Group A (A) and Group B (B). A significant increase of keratometric value was observed in cases with bed thickness of less than $350 \mu \mathrm{m}$ at 10 years after LASIK in both Group A and Group B. Conversely, among cases with bed thickness of more than $350 \mu \mathrm{m}$, there was no statistically significant increase of keratometric value in both Group A and Group B.

Abbreviations: LASIK, laser in situ keratomileusis; Y, years; D, diopter. 


\section{Study limitations}

We would like to mention here that the 10-year visit rate (17.4\%) after LASIK in our clinic may be better than previous reports and the analysis cases were strictly selected and evaluated. However, the limitation of this study included the fact that it was performed in a retrospective manner and analysis cases in 10 years after surgery are relative small number. We also have to consider more sophisticated methods such as OCT and high-resolution ultrasound instrument to measure flap thickness. Furthermore, higher risk for myopic regression by LASIK with a mechanical microkeratome than with a femtosecond laser has been reported. ${ }^{12}$ Prospective examinations in considerations of various factors of myopic regression after surgery will further clarify causes concerning regression of myopia after LASIK.

\section{Disclosure}

The authors report no conflicts of interest in this work.

\section{References}

1. Alió Jl, Muftuoglu O, Ortiz D, et al. Ten-year follow-up of laser in situ keratomileusis for high myopia. Am J Ophthalmol. 2008;145:55-64.

2. Yuen LH, Chan WK, Koh J, Mehta JS, Tan DT; SingLASIK Research Group. A 10-year prospective audit of LASIK outcomes for myopia in 37,932 eyes at a single institution in Asia. Ophthalmology. 2010;117: 1236-1244.

Clinical Ophthalmology

\section{Publish your work in this journal}

Clinical Ophthalmology is an international, peer-reviewed journal covering all subspecialties within ophthalmology. Key topics include: Optometry; Visual science; Pharmacology and drug therapy in eye diseases; Basic Sciences; Primary and Secondary eye care; Patient Safety and Quality of Care Improvements. This journal is indexed on
3. Dirani M, Couper T, Yau J, et al. Long-term refractive outcomes and stability after excimer laser surgery for myopia. J Cataract Refract Surg. 2010;36(10):1709-1717.

4. Alió JL, Soria F, Abbouda A, Peña-García P. Laser in situ keratomileusis for -6.00 to -18.00 diopters of myopia and up to -5.00 diopters of astigmatism: 15-year follow-up. J Cataract Refract Surg. 2015;41:33-40.

5. Ide T, Toda I, Fukumoto T, Watanabe J, Tsubota K. Outcome of 10-year follow-up of laser in situ laser keratomileusis for myopia and myopic astigmatism. Taiwan J Ophthalmol. 2014;4:156-162.

6. Baek T, Lee K, Kagaya F, Tomidokoro A, Amano S, Oshika T. Factors affecting the forward shift of posterior corneal surface after laser in situ keratomileusis. Ophthalmology. 2001;108:317-320.

7. Miyata K, Tokunaga T, Nakahara M, et al. Residual bed thickness and corneal forward shift after laser in situ keratomileusis. J Cataract Refract Surg. 2004;30:1067-1072.

8. Takano M, Yoshida T, Omori K, Ogasawara K, Onodera T. Factors affecting the regression after laser in situ keratomileusis for myopia. Jap Orthopt J. 2005;34:121-126.

9. Chayet AS, Assil KK, Montes M, Espinosa-Lagana M, Castellanos A, Tsioulias G. Regression and its mechanisms after laser in situ keratomileusis in moderate and high myopia. Ophthalmology. 1998;105: 1194-1199.

10. Perlman EM, Reinert SE. Factors influencing the need for enhancement after laser in situ keratomileusis. J Cataract Surg. 2004;20:783-789.

11. Lin HY, Chang CW, Wang HZ, Tsai RK. Relation between the axial length and lenticular progressive myopia. Eye (Lond). 2005;19:899-905.

12. Lin MY, Chang DC, Hsu WM, Wang IJ. Cox proportional hazards model of myopic regression for laser in situ keratomileusis flap creation with a femtosecond laser and with a mechanical microkeratome. J Cataract Refract Surg. 2012;38:992-999.
PubMed Central and CAS, and is the official journal of The Society of Clinical Ophthalmology (SCO). The manuscript management system is completely online and includes a very quick and fair peer-review system, which is all easy to use. Visit http://www.dovepress.com/ testimonials.php to read real quotes from published authors. 